\title{
Caracterização geoambiental do maciço úmido de Maranguape - Ceará: um estudo preliminar
}

\author{
Environmental characterization of the wet mass of Maranguape - Ceará: a preliminary study
}

\author{
Abreu, F. W. R. ${ }^{1}$; Barbosa, G. M. ${ }^{2}$
}

geowilliam05@gmail.com

\begin{abstract}
Resumo
O presente estudo caracteriza os componentes geoambientais do maciço úmido de Maranguape, com área aproximada de $117 \mathrm{~km}^{2}$, situado entre os municípios de Maranguape, Caucaia e Maracanaú, no estado do Ceará, com uma distância média de $27 \mathrm{~km}$ de Fortaleza (capital) e fazendo parte da compartimentação dos maciços pré-litorâneos. Carregando aspectos ambientais distintos das áreas circundantes no semiárido cearense, especificamente das depressões interplanálticas e intermontanas, o maciço úmido em questão apresenta condições fundamentais ligados ao clima, à vegetação, ao solo e à hidrologia que certamente chama a atenção daqueles que almejam utilizar-se da terra e dos recursos naturais que ele dispõe. O estudo em si, feito de forma preliminar, trouxe diversos elementos para o debate geomorfológico e ambiental dentro de um contexto teórico e empírico, onde a serra de Maranguape foi o foco. O resultado da pesquisa pode ser apreciado a partir da caracterização dos componentes geoambientais da área e das suas relações mútuas, onde a estrutura e litologia têm implicações diretas no desenvolvimento do relevo e incide sobre a diversidade de solos, na disponibilidade de recursos hídricos que diretamente afetam no quadro fitogeográfico e nas potencialidades dos recursos naturais disponíveis.
\end{abstract}

Palavras-chave: Componentes geoambientais, maciços cristalinos, paisagem de exceção.

\begin{abstract}
This study characterizes the geo-environmental components of the wet mass of Maranguape, with an approximate area of 117 square kilometers, located between the cities of Maranguape, Caucaia and Maracanaú, State of Ceará, with an average distance of 27 $\mathrm{km}$ from Fortaleza (capital) and doing part of the subdivision of the pre-coastal ranges. Loading different environmental aspects of the surrounding areas in Ceará semiarid region, specifically the interplanálticas and intermontanas depressions, moist mass in question has fundamental conditions linked to climate, vegetation, soil and hydrology that certainly draws the attention of those who aim to be used in land and natural resources that it has. The study itself, made in a preliminary way, brought different elements to the geomorphological and environmental debate within a theoretical and empirical context, where the Maranguape saw was the focus. The search result can be enjoyed from the characterization of geo-environmental components of the area and their mutual relations, where the structure and lithology have direct implications for the development of relief and focuses on the diversity of soil and availability of water resources that directly affect in phytogeographic framework and the potential of available natural resources.
\end{abstract}

Keywords: Geo-environmental components, crystalline massifs, exception landscape.

\section{INTRODUÇÃO}

O semiárido cearense envolve uma área de $126.514,87 \mathrm{~km}^{2}$, equivalentes a $81,52 \%$ de sua área territorial $\left(148.887,632 \mathrm{~km}^{2}\right)$, englobando cerca de 150 munícipios (BRASIL, 2005). Dentre estes está Maranguape, município componente da Região Metropolitana de Fortaleza, que carrega características ambientais concomitantes e, também, diferenciadas daqueles circundantes. Trata-se de uma área em que situa uma paisagem de exceção apresentada a partir de um maciço residual com direção NE-SW. 
Segundo Dantas et al. (2014), os maciços residuais cristalinos excedem em altitude as superfícies de aplainamento que estruturam a depressão sertaneja. Ajustam-se em relevos residuais com dimensões variadas, apresentando altimetrias que variam entre 600 e 1.100 metros no estado do Ceará. Estas formações montanhosas foram geradas por processos de erosão diferencial e, dependendo da estrutura, podem ser compostas por rochas magmáticas ou metamórficas.

Sendo o domínio morfoestrutural com abrangência espacial marcante, a área dos escudos e os maciços antigos são formados por tipos de rochas impermeáveis datadas do Pré-cambriano (SOUZA, 1988). Quando constituem brejo de altitude, esses relevos se espalham pelas depressões sertanejas como "ilhas", diversificando a paisagem do semiárido cearense. Essas "ilhas" de florestas úmidas, composta por mata atlântica, divergem das condições ecológicas das regiões marcadas pela ocorrência de secas prolongadas (CAVALCANTE et al., 2015).

Os maciços residuais recebem diversas denominações, tais como: "serras úmidas", "enclaves úmidos" e "brejos", caracterizados pela influência de mesoclimas de altitude (SOUZA; OLIVEIRA, 2006). Para Ab'Sáber (1974) a importância que os “brejos” tem para o semiárido se assemelha aos "oásis" para as regiões desérticas. Isso vai se constatar nas melhores condições ambientais e de recursos naturais ligados ao clima, à vegetação, ao solo e à hidrologia que estes ambientes apresentam em comparação a áreas topograficamente mais baixas.

No contexto apresentado, a serra de Maranguape, com área aproximada de $117 \mathrm{~km}^{2}$ (MARQUES E SOUZA, 2014), localizada a uma distância média de $27 \mathrm{~km}$ de Fortaleza e tendo como ponto mais elevado a Pedra da Rajada, com 920m, faz parte da compartimentação denominada maciços pré-litorâneos do estado do Ceará. Além dele fazem parte as serras de Uruburetama e Aratanha (SOUZA, 1988). As características morfológicas e ambientais são semelhantes nesses maciços úmidos.

Torna-se profícuo o estudo do maciço úmido de Maranguape, a partir da análise geoambiental e das relações entre seus componentes, por conta da importância socioambiental que esta tem com a população do município homônimo. Além disso, parte-se, ainda, da preocupação referente aos usos da terra e dos recursos naturais que o próprio dispõe.

Ter a compreensão da dinâmica ambiental do referido maciço úmido é de suma importância para a conservação e preservação dos cursos d'águas, assim como, da vegetação e dos solos que a recobre.

Face às preposições citadas, o presente trabalho tem por objetivo fazer uma caracterizarização geoambiental da serra de Maranguape, considerando os seus componentes ambientais, assim como os aspectos geológicos, geomorfológicos, hidroclimáticos, pedológicos, fitogeográficos e suas relações recíprocas. Compreender como os componentes se organizam e se 
articulam entre si é primordial para identificar os principais problemas de uso e o estado atual dos recursos naturais.

\section{METODOLOGIA}

Abrangendo maior número de perspectivas a serem alcançadas e mostrando respostas aos objetivos do trabalho desenvolvido, a metodologia tem a conveniência de nortear os caminhos que são importantes para o desenvolvimento da pesquisa. Considerando essa necessidade, o trabalho foi segmentado em três partes. Inicialmente, o levantamento bibliográfico sobre o assunto foi de grande importância para a construção da pesquisa. Utilizaram-se materiais publicados em livros, artigos e dissertações. Todas voltadas para a caracterização da forma do relevo e de seus condicionantes, assim como para a análise geoambiental do maciço úmido.

Além disso, foram utilizados levantamentos cartográficos do estado do Ceará e, especificamente, da cidade de Maranguape, aproveitando-se principalmente de mapas temáticos, como o mapa geológico produzido pela CPRM (2003) na escala de 1:500.000 e, para uma melhor espacialização da área de estudo, utilizou-se de imagem SRTM (Shuttle Radar Topography Mission).

A etapa seguinte, a da pesquisa de campo, constituiu-se de registros fotográficos e investigações empíricas mais detalhadas da região. Procedeu-se à observação de fatos e fenômenos que o embasamento teórico não contemplava, enriquecendo o trabalho. A vantagem de ter ido ao campo resultou na aquisição de conhecimento direto da realidade estudada, possibilitando, na análise descritiva, maior riqueza de detalhes.

É a partir dessa etapa que se propôs outra, a da integração dos dados obtidos e do trabalho de gabinete pela pesquisa bibliográfica e de campo.

\section{RESULTADOS E DISCUSSÃO}

A caracterização dos componentes ambientais do maciço úmido de Maranguape é importante para o entendimento da estrutura e funcionamento do ambiente em estudo e sua relação com a sociedade. Concordando com Cordeiro, Garcez e Bastos (2014, p. 140), 
hidroclimatologia, pedologia e fitoecologia, sob uma ótica sistêmica, associados aos fatores socioeconômicos.

A serra de Maranguape, considerada um ambiente de exceção no semiárido cearense assim como as serras de Baturité, Meruoca, Uruburetama e Aratanha no estado do Ceará -, em seus pontos mais salientes contém intricada cobertura vegetal que atua como um verdadeiro refúgio para os animais e se dispõe como condição relevante para a manutenção de várias nascentes de rios e para determinar o clima distinto da área. Souza $(2011$, p. 20) vai afirmar que no ambiente serrano " $O$ modo como os componentes naturais mantêm suas relações mútuas é muito característico e o relevo tem sempre um papel decisivo através da altimetria elou da exposição".

Posicionada próxima à linha de costa e com uma vertente a barlavento (setor oriental) (Mapa 01), favorecendo a fixação de um considerável contingente demográfico, a serra de Maranguape sofre as influências da orientação (NE-SW), da localização e da altitude (superior a $600 \mathrm{~m}$ ), proporcionando a verificação de setores distintos daqueles situados nas depressões interplanálticas e intermontanas semiáridas na perspectiva ambiental (SOUZA; LIMA; PAIVA, 1979).
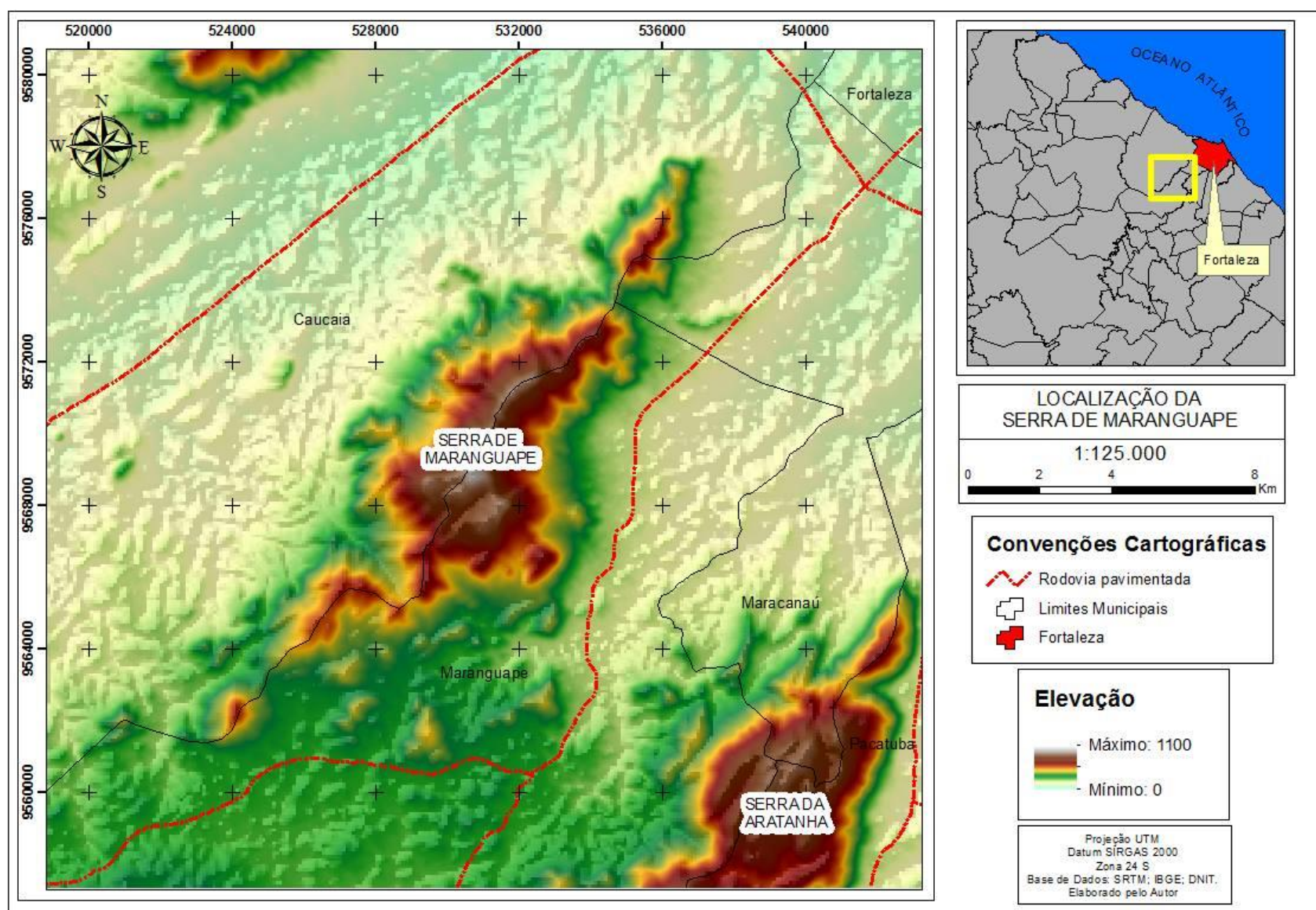

Mapa 01. Localização da serra de Maranguape. Fonte: CAVALCANTE, D. R. (2016) 
Segundo Cordeiro, Garcez e Bastos (2014), o substrato geológico do maciço úmido de Maranguape está representado pelo Complexo Granitóide-Migmatítico encontrado na Unidade Canindé (DANTAS et al., 2003), onde as exposições marcantes estão situadas nos setores morfologicamente mais altos. A origem do relevo serrano pode ser explicada a partir dos processos de erosão diferencial, isto é, pelo desgaste desigual dos corpos rochosos por conta do contrate de resistência que determinada rocha contém. Neste caso houve o rebaixamento das áreas gnáissicas circundantes e as áreas resistentes ficaram representadas por granitóides (CORDEIRO; GARCEZ; BASTOS, 2014).

A estrutura dessa área foi submetida a um tectonismo intenso que se caracteriza por zonas fraturadas, dobradas e falhadas, traduzindo-se em feições morfológicas escarpadas (SOUZA; OLIVEIRA, 2006).

Caracterizada por estudos geomorfológicos como sendo um maciço pré-litorâneo, incluído no domínio dos Escudos e Maciços Antigos, a serra de Maranguape é constituída por litologias do embasamento cristalino, oriundos do pré-Cambriano (SOUZA, 1988). As formas de relevo que a constituem demonstram os eventos tectônico-estruturais do passado geológico dos maciços antigos metamorfizados e submetidos às influências de tectonismo plástico e ruptural (SOUZA, 2000).

Sobre o relevo serrano de Maranguape é possível reconhecer, sobretudo, uma divisão em partes altimétricas distintas, onde somente a porção central alcança altitudes acima dos 600 metros. Essa parte é bastante representativa quando relacionada à interferência climática local, submetendo o maciço úmido à ação das chuvas orográficas e propiciando um escoamento fluvial acentuado a partir de solos impermeáveis. A junção destes dois elementos irão nortear os processos erosivos que ocorrem sobre a superfície da serra, determinando as características geomorfológicas (ARRUDA, 2001).

Cordeiro (2013) afirma que por conta da impermeabilidade das rochas cristalinas e das condições mais úmidas do maciço, existe o adensamento da drenagem e o seu aprofundamento da superfície, que provocam ações de dissecação, determinando a acidentação do relevo nas formas de cristas aguçadas, colinas convexas e topos planos. Estes se alternam em vales estreitos em forma de "V" alargados nos setores de suavização topográfica. Complementando, Arruda (2001) diz que é no topo onde se encontram as dissecações mais visíveis da serra de Maranguape, com declives que chegam a $45 \%$.

O topo úmido e a vertente oriental comprovam um alto índice pluviométrico resultando em uma densa rede fluvial, com padrões de drenagem dendrítico e sub-drendrítico como principais representantes (ARRUDA, 2001). As colinas, em setores mais rebaixados do compartimento serrano, são mais suaves e suas vertentes têm declives menores, ficando em torno de 10 e $15 \%$. Isso 
demonstra uma menor capacidade de entalhamento da superfície pela rede de drenagem (SOUZA; OLIVEIRA, 2006).

Na perspectiva hidrológica percebe-se que o escoamento fluvial consiste da conjugação de fatores como o clima, a natureza dos terrenos, os condicionantes geomorfológicos e a densidade da cobertura vegetal (CORDEIRO; GARCEZ; BASTOS, 2014). Consequente a isto e a impermeabilidade do terreno, a região circundante ao maciço úmido é abundante em açudes (reservatórios de água), sustentada por riachos serranos. Cordeiro, Garcez e Bastos (2014) afirmam ainda que é na vertente oriental que se encontram os três principais rios - como o Pirapora, Gavião e Tangueira - e juntamente com os outros pequenos riachos deságuam no rio Maranguapinho, tendo seu destino final no rio Ceará.

Por está situado próximo ao litoral, o maciço úmido de Maranguape tem os índices pluviométricos elevados, com médias anuais em torno de $1.380 \mathrm{~mm}$ (CEARÁ, 2015). O tipo climático, em concordância com o sistema de classificação de Köppen e predominado pelo mesoclima da faixa costeira cearense, é o tropical chuvoso quente úmido, com temperaturas entre $23^{\circ}$ (mínima) e $28^{\circ}$ (máxima), com chuvas abundantes entre os meses de janeiro a maio. Este sofre "influência da ação combinada da altitude e da exposição do relevo, face aos deslocamentos de massas de ar úmidas" (CORDEIRO; GARCEZ; BASTOS, 2014, p. 140).

Com relação aos solos que recobrem o maciço úmido, é possível destacar algumas associações nas classes, com certas predominâncias. Souza e Oliveira (2006) destacam que os Argissolos Vermelhos-Amarelos Eutróficos são a maior parte, prevalecendo-se no platô da serra e estão relacionados aos relevos colinosos, as lombas alongadas e aos estreitos interflúvios tabulinares, com perfis medianamente profundos e muito profundos com fertilidade natural de média e alta. Os Neossolos Litólicos Eutróficos acomodam-se sobre as áreas de cristas ou vertentes mais íngremes onde é regular a sua incidência associada aos afloramentos rochosos. Seus perfis são rasos e muito rasos, pedregosos e têm média a alta fertilidade natural. Os Neossolos Flúvicos ocupam as planícies alongadas e os alvéolos com fertilidade natural que varia de média a alta.

Sobre a caracterização e distribuição da cobertura vegetal que reveste a serra, Fernandes (1998) destaca três grandes unidades vegetacionais: o Arboreto Climático Estacional Caducifólio, Arboreto Climático Estacional Semicaducifólio e Arboreto Climático Perenifólio. Para Cordeiro, Garcez e Bastos (2014), nos setores mais úmidos do maciço residual a certo recobrimento de floresta pluvionebular subperenifólia, diferentemente do sopé, que é coberto por uma mata seca semicaducifólia que vai ocupando as superfícies mais baixas. Destaca-se, deste ponto, uma vegetação de transição, que entra em discordância com a paisagem sertaneja, revestida por diferentes tipos de caatinga e por pequenas manchas de mata ciliar. Souza e Oliveira (2006) 
salientam que a vegetação primária, composta por floresta subperenifólia, só restam apenas manchas "testemunhas", comprovando o estado de degradação avançado em função do uso agrícola intenso e também devido à ocupação desordenada na serra.

\section{CONSIDERAÇÕES FINAIS}

Apreender como ocorrem as relações entre os componentes geoambientais (geologia, geomorfologia, hidroclimatologia, pedologia e fitogeografia) de um maciço úmido, dentro de um contexto de semiaridez no Estado do Ceará, é proveitoso no sentido de que se pode construir um quadro socioambiental necessário para intervir nas ações antrópicas e, simultaneamente, lançar ideias que envolvam a conservação e preservação sobre este ambiente.

O estudo em si, feito de forma preliminar, trouxe diversos elementos para o debate geomorfológico e ambiental dentro de um contexto teórico e empírico, onde a serra de Maranguape foi o foco em questão.

Dessa forma, o resultado da pesquisa pode ser apreciado a partir da caracterização dos componentes geoambientais da área e das suas relações mútuas, onde o homem não pode estar fora deste contexto. A estrutura e litologia do maciço úmido de Maranguape têm implicações diretas no desenvolvimento do relevo e incide sobre a diversidade de solos e na disponibilidade de recursos hídricos que diretamente afetam no quadro fitogeográfico e nas potencialidades dos recursos naturais disponíveis.

Sobre a atuação do homem no ambiente serrano, constatou-se que a vegetação foi o principal elemento a ter sofrido impacto. A retirada da cobertura vegetal deu-se a partir do uso indiscriminado do solo, através da agricultura e da construção de habitações nas encostas e nos topos. As consequências dessa apropriação desordenada podem acarretar no aumento da erosão dos solos e no assoreamento dos pequenos riachos e rios que cortam a serra, impossibilitando que os reservatórios de água sejam preenchidos devido a pouca vazão.

Almeja-se, com as contribuições apresentadas, que estas possam servir para nortear caminhos mais complexos e aprofundados sobre a caracterização geoambiental de maciços úmidos no Estado do Ceará, principalmente através de pesquisas acadêmicas, e, consequentemente, atuar como ponte para guiar políticas públicas referentes ao uso sustentável da terra e dos recursos naturais aos quais os maciços dispõem. 


\section{REFERÊNCIAS}

AB'SÁBER, A. N. O domínio morfoclimático semi-árido das caatingas brasileiras.

Geomorfologia, São Paulo, Instituto de Geografia, n. 43, p. 1-37, 1974.

ARRUDA, L. V. Serra de Maranguape-CE: Ecodinâmica da paisagem e implicações

socioambientais. 162p. Dissertação (Mestrado em Desenvolvimento e Meio Ambiente) -

Universidade Federal do Ceará, Fortaleza. 2001.

BRASIL. Ministério da Integração Nacional. Secretaria de Políticas de Desenvolvimento Regional (SDR). Relatório Final do Grupo de Trabalho Interministerial para Redelimitação do Semiárido Nordestino e do Polígono das Secas. Brasília: Ministério da Integração Nacional, 2005. Disponível em: http://www.cpatsa.embrapa.br/public_eletronica/downloads/OPB1839.pdf. Acesso em: 17 jul. 2016.

CAVALCANTE, D. R.; BASTOS, F. H.; CORDEIRO, A. M. N.; SILVA, F. L. Um estudo preliminar sobre a geomorfologia do maciço de Maranguape, Ceará, Brasil. In: SIMPÓSIO BRASILEIRO DE GEOGRAFIA FÍSICA APLICADA, 16., Anais. Teresina, PI: Universidade Federal do Piauí/Universidade Estadual do Piauí, 2015. p. 2149-2155. Disponível em: http://www.sbgfa.ggf.br/2015/arquivos/anais.rar. Acesso em: 22 jul. 2016.

CAVAlCANTE, J. C.; VASCONCELOS, A. M.; MEDEIROS, M. F.; PAIVA, I. G. Mapa Geológico do estado do Ceará. Fortaleza: CPRM, 2003. Escala 1:500.000. Disponível em: http://rigeo.cprm.gov.br/xmlui/bitstream/handle/doc/2355/Mapa\%20Geologico.pdf?sequence=1. Acesso em: 22 jul. 2016.

CEARÁ. Secretaria do Planejamento e Gestão. Instituto de Pesquisa e Estratégia Econômica do Ceará (IPECE). Perfil básico municipal 2015 Maranguape. Fortaleza: Instituto de Pesquisa e Estratégia Econômica do Ceará, 2015. Disponível em:

http://www.ipece.ce.gov.br/publicacoes/perfil_basico/pbm-2015/Maranguape.pdf. Acesso em: 17 jul. 2016.

CORDEIRO, A. M. N. Análise socioambiental da sub-bacia hidrográfica do rio PiraporaMaranguape/Ceará, como subsídio ao planejamento territorial e à gestão ambiental. 166p.

Dissertação (Mestrado em Geografia) - Universidade Estadual do Ceará, Fortaleza. 2013. Disponível em: http://www.uece.br/mag/dmdocuments/abner_cordeiro_dissertacao.pdf. Acesso em: 23 jun. 2016.

CORDEIRO, A. M. N.; GARCEZ, D. S.; BASTOS, F. H. A influência dos componentes geoambientais e das intervenções antropogênicas nos movimentos de massa na sub-bacia hidrográfica do rio Pirapora, Maranguape-Ceará. Revista Geografia Ensino \& Pesquisa, Santa 
Maria, v. 18, n. 1, p. 135-154, jan./abr. 2014. Disponível em: http://periodicos.ufsm.br/geografia/article/view/7779. Acesso em: 22 jul. 2016. DANTAS, M. E.; SHINZATO, E.; BRANDÃO, R. L.; FREITAS, L. C. B.; TEIXEIRA, W. G. Origem das paisagens. In: BRANDÃO, R. L.; FREITAS, L. C. B. (org.). Geodiversidade do estado do Ceará. Fortaleza: CPRM, 2014. p. 35-60. Disponível em: http://www.cprm.gov.br/publique/media/Geodiversidade_CE.pdf. Acesso em: 22 jul. 2016. FERNANDES, A. Fitogeografia brasileira. Fortaleza: Multigraf, 1998. 340p.

MARQUES E SOUZA, Guilherme. Modelagem ambiental para a delimitação de brejos de altitude com estudos de casos para os maciços da Aratanha, Maranguape, Juá e Conceição - Estado do Ceará. 138p. Dissertação (Mestrado em Geografia) - Universidade Estadual do Ceará, Fortaleza. 2014. Disponível em: http://www.uece.br/mag/dmdocuments/guilherme_marquese_souza1.pdf. Acesso em 30 jun. 2016.

SOUZA, M. J. N. Bases naturais e esboço do zoneamento geoambiental do estado do Ceará. In: LIMA, L. C. (org.). Compartimentação territorial e gestão regional do Ceará. Fortaleza: FUNECE, 2000. p. 6-105. . Contexto ambiental do enclave úmido da serra de Baturité-Ceará. In: BASTOS, F. H. (org.). Serra de Baturité: uma visão integrada das questões ambientais. Fortaleza: Expressão Gráfica e Editora, 2011. p. 19-34. . Contribuição ao estudo das unidades morfo-estruturais do estado do Ceará. Revista de Geologia, Fortaleza, v. 1, n. 1, p. 73-91, jun. 1988.

SOUZA, M. J. N.; LIMA, F. A. M.; PAIVA, J. B. Compartimentação topográfica do Estado do Ceará. Revista Ciência Agronômica, Fortaleza, v. 9, n. 1-2, p. 77-86, dez. 1979. Disponível em: http://www.ccarevista.ufc.br/site/down.php?arq=12rca9.pdf. Acesso em: 23 jul. 2016.

SOUZA, M. J. N.; OLIVEIRA, V. P. V. Os enclaves úmidos e sub-úmidos do semi-árido do nordeste brasileiro. Revista Mercator, Fortaleza, v. 5, n. 9, p. 85-102, jan./jun. 2006. Disponível em: http://www.mercator.ufc.br/index.php/mercator/article/view/91/63. Acesso em: 22 jul. 2016.

\section{AGRADECIMENTOS}

Ao Laboratório de Estudos Morfoestruturais e Pedológicos (LEMEP), da Universidade Estadual do Ceará, no nome do Professor Doutor Frederico de Holanda Bastos e dos bolsistas Daniel dos Reis Cavalcante e Luciana Sousa Mendes, pelo acolhimento e receptividade quando precisei desbravar novos caminhos e estudos, principalmente enveredando para o lado da geomorfologia. 
Recebido em: 14/08/2016

Aceito para publicação em: 01/10/2016 